U N IVERSITY OF COPENHAGEN

\title{
Naturalistic Epistemology
}

Kappel, Klemens

Published in:

Routledge Companion to Epistemology

Publication date:

2010

Document version

Publisher's PDF, also known as Version of record

Citation for published version (APA):

Kappel, K. (2010). Naturalistic Epistemology. In Routledge Companion to Epistemology (pp. 836 - 847).

Routledge. 


\section{Naturalistic epistemology}

by Klemens Kappel, Philosophy, University of Copenhagen

kappel@hum.ku.dk

\section{Introduction}

Naturalistic epistemology names a cluster of views according to which epistemology should be reconciled with, or even draw upon, empirical science. By contrast, traditional epistemology assumes that epistemology is prior to and independent of empirical science, both in terms of its subject matter and in terms of its methods. The details of this are complicated and there are now many different views championed under the heading of naturalistic epistemology.

It is useful to make a rough distinction between two enterprises in epistemology. The descriptive project aims to understand the basic nature of matters epistemic, that is, the nature of epistemic properties, states, norms, aims, concepts, expressions, practices of epistemic evaluations (henceforth I will just write 'epistemic notions'). Thus the descriptive project asks questions as: What is knowledge? What is it for a belief to be justified? What is an epistemic norm? What is it to say that a belief is known? The normative project, by contrast, seeks to advance and justify epistemic evaluations. Do our beliefs really qualify as justified? Are the beliefs usually regarded as known rightly so judged? Are we doing right in adopting the epistemic norms that we rely upon in our epistemic practices? What would improved epistemic practices be? Note that the normative project includes, but is not exhausted by, what is sometimes called meliorative epistemology, the attempt to improve on our ways of reasoning.

Corresponding to the descriptive and the normative project, one can discern two distinct classes of naturalistic views, which I will refer to as descriptive naturalism and normative naturalism (Laudan 1990).

Traditionally, epistemology has been conducted using philosophical methods, that is methods that allegedly proceed by means of conceptual analysis, linguistic analysis, a priori insights, considered intuitions about how to classify possible cases, and attempts to reach reflective equilibrium between these possibly conflicting inputs and other theoretical commitments. Philosophical methods are non-empirical in that they appeal only to what can be justifiably believed or known without conducting empirical investigations of the external world.

By contrast, methodological naturalism is the view that empirical investigations should partly or entirely replace philosophical methods. So, a methodological naturalist about the descriptive project thinks that, roughly, when determining what knowledge is, we should in part or entirely turn to empirical investigations, say in cognitive science or psychology. Methodological naturalism about the normative project advocates make use of empirical findings when addressing questions within the normative project.

These different forms of naturalisms are typically related in being motivated by more a more general naturalistic outlook, but they are nonetheless logically distinct. One can be a descriptive naturalist without being a normative naturalist, and vice versa. And one can accept methodological naturalism about 
the normative project, without endorsing it about the descriptive project, or conversely.

\section{Quine's 'Epistemology naturalized'}

The recent history of the subject dates back to W.V. Quine's widely read paper 'Epistemology Naturalized'. Here Quine famously held that epistemology should fall 'into place as a chapter of psychology', confining itself to the study of how subjects generate beliefs about the world as a function of the input they receive. For Quine, this study of the 'relation between the meager input and the torrential output' should be undertaken for 'somewhat the same reasons that always prompted epistemology; namely, in order to see how evidence relates to theory, and in what ways one's theory of nature transcends any available evidence.' (Quine 1969)

As has often been observed, it difficult to see how Quine's naturalism could plausibly be a successor discipline to traditional epistemology (Bonjour 1994: 287; Kim 1988). The descriptive project asks about the nature of epistemic notions such as knowledge or justified belief. Studying the 'relation between the meager input and the torrential output' could be an attempt to eliminate such questions, but would hardly settle them. A crucial part of the normative project is to decide if our everyday and scientific beliefs about the world are in fact justified. Again, is hard to see how a mere description of how we in fact proceed when forming beliefs could be a new way of answering those questions. In later writings Quine has, however, clarified his position and explicitly asserted a normative role of epistemology, saying in one place that normative epistemology is 'a branch of engineering', seeking to aid the 'technology of truth-seeking' (Quine 1986; Foley 1994).

Irrespective of perceived weaknesses of Quine's 'Naturalized Epistemology', many influential epistemologists endorse naturalistic views. Important recent contributions include (Goldman 1986a; Kitcher 1992; Kornblith 2002; Bishop 2005). Prominent critics of naturalistic epistemology are plenty, and include Laurence BonJour, Richard Feldman, Michael Williams, Barry Stroud, Donald Davidson and Robert Brandom, just to mention a few. A recent useful discussion of objections to naturalistic epistemology is found in (Kornblith 2002), especially chapters 3,4 and 5 .

\section{Descriptive naturalism}

Descriptive naturalism claims that the nature of epistemic notions can be accounted for in natural terms, i.e. terms referring exclusively to natural objects and properties. Natural objects and properties are such as would figure in our best scientific understanding of the world.

Descriptive naturalism remains a controversial position. Knowledge is, by most accounts, true belief acquired or sustained for good epistemic reasons, with sufficient evidence, or in non-accidental ways (ignoring Gettier complications). However, notions such as having a good epistemic reason, or sufficient evidence for holding a belief do not figure as a part psychology or cognitive science, and neither does a belief's property of being non-accidentally acquired. So states of knowledge do not immediately seem to be composed entirely natural objects and properties. Similarly, a complete naturalistic description of a cognitive process 
would seem to leave open whether this process would count as embodying a proper epistemic norm or not.

Those inclined to naturalism about the descriptive project have responded to this set of questions in a variety of rather different ways. Eliminativist have repudiate the normative side of epistemic notions altogether, in favor of an enterprise that merely seeks to describe the ways in which beliefs are actually formed. Quine, in 'Epistemology Naturalized' held this sort of view (see (Maffie 1990) for a helpful overview and further references).

Since eliminativism may be said to repudiate rather than account for epistemic notions, this position may not be considered a form of naturalistic epistemology at all. Other strategies do not seek to eliminate the normative dimension of epistemic properties, but to account for them. To provide a less abstract presentation of some basic ideas within this family of strategies, it may be helpful to consider a more specific theory of justification and knowledge:

Reliabilism. Beliefs are justified to the extent that they are acquired or sustained by a reliable process. Beliefs are known when true and sufficiently justified.

Relibilism and similar views have been defended by Alvin Goldman and many others (Goldman 1979; Goldman 1986b; Goldman 1992b). Reliabilism is but one member of a wider class of externalist theories which hold that beliefs may be justified (or known if true) in virtue of features that are external to the purview of the subject, but for present purposes, we need not consider the wider class of externalist theories. It is important to note though, that nothing in descriptive naturalism per se forces one to be an externalist about knowledge or justification. It is just that many proponents of descriptive naturalism have adopted some form of reliabilism or externalism about knowledge and justification, whereas those opposed to naturalism tend to be internalists about knowledge and justification.

A descriptive naturalist who accepts reliabilism may propose this view as a naturalistically acceptable analysis of our concepts of justification and knowledge. Closely related, one might consider reliabilism as offering a reduction of epistemic to natural properties. Recently, Kornblith has defended the view that knowledge is a natural kind, just as water or aluminium are natural kinds. Reliabilism, on Kornblith's view, figures as a part of the account of the natural properties that constitute knowledge as a natural kind. (Kornblith 2002). A less ambitious option is to view reliabilism in criterialist terms. According to this view, reliabilism specifies the conditions for the proper application of epistemic predicates, but refrains from providing an analysis or reduction of those predicates. Hence, the criterialist concedes that 'epistemic predicates cannot be naturalistically defined or reduced without loss of their essential content' (Maffie 1990: 285). In later work, Goldman has embedded reliabilism in an empirically supported naturalistic view of how epistemic evaluators apply the concepts of knowledge and justification (Goldman 1992a).

All non-eliminativist versions of descriptive naturalism agree that epistemic properties depend on natural properties: 
Supervenience. For any epistemic property $\mathrm{E}$, and any agent $\mathrm{x}$ and $\mathrm{y}$, if $\mathrm{x}$ has $\mathrm{E}$, there is a set of natural properties $\mathrm{N}$, such that $\mathrm{x}$ has $\mathrm{N}$, and necessarily, whatever agent $\mathrm{y}$ has $\mathrm{N}$ y also has $\mathrm{E}$.

Supervenience, or similar views, have been widely endorsed (Van Cleve, 1985) (Van Cleve, 1999, Goldman, 1994, Kim, 1988), though there are noteworthy dissenters (Lehrer, 1999). It is important to realize, however, that while involving some degree of naturalism, supervenience is compatible with epistemic properties being genuine but non-natural, and hence not analyzable or reducible to natural objects and properties.

\section{Accounting for the normativity of the epistemic}

Non-eliminativist forms of descriptive naturalism may seem to face a problem accounting for the distinctive normative dimension of the epistemic. There is a sense in which one ought to acquire beliefs in certain ways, or ought to believe certain things when in possession of particular evidence or reasons. How is this 'to-do-ness' or the 'ought-to-believe-ness' supposed to flow from an austere account of the natural properties that epistemic properties consist of? This problem is, of course, reminiscent of the problem J. L. Mackie pointed out in ethics (Mackie 1977; Kornblith 2002: chapter 5).

For simplicity, consider the problem specifically in terms of epistemic norms. Let us say that an epistemic norm is a directive, principle or rule stating a way to adopt, revise or sustain beliefs. Epistemic norms may be embodied in an individual subject's modes of reasoning and methods of inquiry, or they may be embodied in socially embedded epistemic practices, such as those found in science or public debate. We may rely on particular epistemic norms even when we are not aware of doing so, or unable to explain what if anything justifies us in doing so.

Let us say that a proper epistemic norm is one that we are epistemically permitted to make use of, given appropriate circumstances. Induction is a proper epistemic norm (or set of norms), whereas crystal ball gazing or affirming the consequent is not. So, proper epistemic norms exert some sort of normative force: given appropriate conditions, one ought to make use of them. Any view in epistemology must account for the purported normative force of proper epistemic norms. What is the descriptive naturalist account of the normative force of proper epistemic norms?

A common option is to think of epistemic norms as hypothetical imperatives. Relative to particular ends, certain ways of reasoning or acquiring beliefs may be more or less expedient in various circumstances. So, for example, one might say that for a subject $S$ and some appropriate end $E$, epistemic norm EN is proper just in case relying on EN makes $S$ sufficiently adept at arriving at $E$ under the conditions in which S would normally use EN to arrive at E.

Quine subscribed to this sort of view, holding that epistemic norms are instruments relative to the aim of finding truth, which on Quine's view appears to be a purely contingent aim (Quine 1986). Stephen Stich advocates a very general form of pragmatism according to which an agent's set of epistemic norms should be assessed in terms of their contribution to the total set of things the agent values (Stich 1990: 131-2). Kornblith, in recent work, has criticized both of these views and argued that while epistemic norms are indeed 
hypothetical imperatives, the merits of a system of epistemic norms should be assessed not relative to contingent aims, but relative to the aim of truth, which we are bound to care about 'whatever we may otherwise care about' (Kornblith, 2002: 158).

Another and quite different strategy that might suit the descriptive naturalist is to adapt the expressivist account of normativity that is well-known from ethics (Gibbard 1990; Gibbard 2003; Blackburn 1998). This view, which is only sparsely elaborated, is now referred to as epistemic expressivism. Epistemic expressivism holds that epistemic expressions are not fully descriptive but at least partly expressive. Thus, uttering sentences of the form ' $\mathrm{S}$ knows that $\mathrm{p}$ ' normally serve to express a distinct kind of pro-attitude to subjects' holding certain beliefs. Similarly, saying that some epistemic norm is proper is expressing one's pro-attitude towards the use of that norm. Hartry Field is a proponent of epistemic expressivism (though he calls it non-factualism) (Field 1998), and a similar view has been defended in (Chrisman 2007). Recently, epistemic expressivism has been criticized in (Cuneo 2007) and (Kvanvig 2003)

\section{Normative naturalism}

The normative project concerns the epistemic evaluation of our ways of reasoning and conducting inquiry. When we judge that beliefs are justified or known, are we right? When we rely on specific modes or forming beliefs or patterns of inference, are we doing right? Could we improve on our ways of reasoning? Note that issuing and justifying epistemic evaluations of beliefs and epistemic norms is different from accounting for the normative dimension of epistemic properties, which is part of the descriptive project.

Normative naturalism holds that when addressing the questions of the normative project, we can in certain ways appeal to everyday beliefs about the world, as well as to empirical findings from disciplines such as psychology and cognitive science. This position is controversial, and to understand why we need to consider the ways in which the normative project has traditionally been pursued in epistemology.

\section{The privileged class constraint}

The normative project has to a large extent evolved around two more specific set of issues: a range of skeptical challenges, and the problem of how to justify our epistemic norms, where this includes epistemology's meliorative project.

The most prominent of the skeptical challenges, the Cartesian challenge, is this: How can one rule out the possibility of being a brain in a vat, devoid of genuine perceptual contact to the external world? The Lockean challenge is slightly different, and asks roughly: How can we have knowledge about the external world, given all we have to go on are beliefs about our own perceptual experience?

It quite crucial for these skeptical challenges that they come with the following restriction in permissible responses: one cannot appeal to premises the knowledge of which is rendered in doubt by the skeptical challenge in question. So, when responding to the Cartesian challenge, one cannot appeal to empirical facts about how extremely unlikely the scenario in question is, or indeed to what would normally count as observations incompatible with being a brain in a vat. When responding to the Lockean challenge, one cannot appeal to putative empirical facts about correlations between the character of one's sense 
experience and the external world. Thus, the common structure of the skeptical challenges is that they grant that while we are justified in accepting members of a fairly small class of beliefs (the privileged class), we are not justified in a certain other class of beliefs (the target class). The skeptic then charges us with the task of explaining how we are, after all, justified in accepting members of the target class, while appealing only to members of the privileged class. Call this the privileged class constraint.

Clearly, different specific skeptical challenges vary with respect to the extensions of the target class and the privileged class. Very general skeptical challenges admit only a priori justified beliefs in the privileged class (or perhaps only a subclass of these), whereas less general skeptical problems may admit reflectively accessible beliefs, including beliefs about the nature of certain perceptual experiences or memory experiences. The problem of other minds admits beliefs about the overt behavior of others in the privileged class, while beliefs about the mental life of others are to be found in the target class.

Consider then the other part of the normative project, that of justifying our epistemic norms. Is there a cogent argument to the effect that we should trust sense perception? Are we justified in relying on inductive inferences, and if so, in virtue of what? Again, a version of the privileged class constraint is assumed to apply. When replying to the question whether we are justified in relying on some epistemic norm EN, we cannot appeal to EN or otherwise make use of EN. So, when explaining why certain forms of inductive inferences are reasonable, we cannot make use of induction. When explaining why we are permitted to trust sense perception, we cannot rely on the deliverances of sense perception, or on beliefs the justification of which depends on sense perception.

Note that the problem justifying epistemic norms remains distinct from problem of responding to skeptical challenges. For example, one might think that one can reject as incoherent the possibility that one might be a brain in a vat, and yet still be at a loss to explain why we are permitted to rely on inferences to best explanations. But of course, one can mount a skeptical challenge by arguing that some class of our epistemic norms are not reliable, or that we have no reason to consider them reliable.

\section{Ignoring the privileged class constraint}

Throughout the history of epistemology, tremendous efforts have been invested in the attempt to address skeptical challenges and justify epistemic norms while observing the privileged class constraint. For example, many writers have pursued the strategy of mounting transcendental arguments purporting to show that, on a priori grounds, the idea that one might be a brain in a vat is incoherent. Others have attempted to argue on a priori grounds that we should trust sense perception, memory, or rely on induction. For example, P.F Strawson once held it to be an a priori knowable truth that we are permitted to rely on induction, since the use of induction under appropriate circumstances is part of 'what 'being reasonable' means in such a context.' (Strawson 1952: 257). BonJour has recently offered a general defense of a priori reasoning which includes an a priori defense of induction (Bonjour 1998). Such strategies would, if otherwise successful, provide a vindication of certain of our epistemic norms, while still observing the privileged class constraint. 
Perhaps the single most important and controversial contribution of naturalistic epistemology is to advocate ignoring the privileged class constraint. When facing skeptical challenges, and when evaluating epistemic norms, we are not obliged to observe the privileged class constraint.

There are different ways of pursuing this strategy. One example is P.F Strawson, who in his Woodbridge Lecture 'Skepticism, Naturalism and Transcendental Arguments', advocated thinking of 'skeptical arguments and rational counter-arguments as equally idle - not senseless, but idle - since what we have here are original, natural inescapable commitments which we neither choose nor could give up' (Strawson 1985: 27-8). Strawson here seems to concede to the skeptic that, properly speaking, we are not really justified in a range of our beliefs, just as we are incapable of providing a satisfactory demonstration that our epistemic norms are proper. It is just, says Strawson, that we cannot really change our minds on these issues. In this sense, Strawson recommends ignoring the privileged class constraint.

Another example is, again, Quine, who insisted on 'the point that sceptical doubts are scientific doubts', which for Quine meant that they can and should be answered by scientific means (Quine 1975: 68). Goldman says something very similar: 'In studying and criticizing our cognitive procedures, we should use whatever powers and procedures we antecedently accept. There is no starting "from scratch"' (Goldman 1978: 522). Kitcher concurs, when he concedes that on 'naturalism's own ground, there are bound to be unanswerable forms of skepticism', and adds that the 'naturalists should therefore decline blanket invitations to play the game of synchronic reconstruction'. Rather, 'parts of our current scientific beliefs must be assumed in criticizing others' (Kitcher 1992: 90-1).

An important question raised by these normative naturalist strategies concerns their wider epistemological implications. Here one can distinguish two views. Weak normative naturalism urges that we can ignore the privileged class contraint and make use of empirical findings and ordinary beliefs about the world when pursuing the normative project. But, the weak normative naturalist concedes, one does beg the question against the skeptic by violating the privileged class constraint. In consequence we should give up the hope of providing a genuine justification of our epistemic norms and a genuine demonstration that much of what we take to be known is indeed so. What we have is a kind of naturalistic ersatz for the normative judgments that (naïve) traditional epistemology in vain sought to underpin while observing the privileged class constraint. Strawson, Quine and possibly Kitcher seem to acquiesce to this view. Bishop and Trout explicitly endorse it (Bishop and Trout, 2005b: 161).

Strong normative naturalism, by contrast, insists that thus begging the question against the skeptic has no wider epistemological implications. The fact that we cannot, without begging the question, demonstrate the propriety of our epistemic norms in the face of a skeptical challenge, does nothing to show that we are not epistemically justified in relying on those epistemic norms. The fact that we cannot rule out a skeptical scenario to the skeptic's satisfaction does not imply that we have virtually no knowledge or justified beliefs about the world. 


\section{Is strong normative naturalism tenable?}

To see how strong normative naturalism might be a defensible position, return again to reliabilism. Part of the normative project is to explain the epistemic status of our beliefs and the epistemic norms we use or might use. Consider what reliabilism implies about these questions. When our beliefs are formed by reliable processed, they are justified. When true in addition, our beliefs are known. Now, in many cases, we have, or are in position to acquire, justified beliefs to the effect that specific beliefs of ours are indeed reliably formed and true, and thus instances of knowledge. So, granted reliabilism and certain seemingly innocuous beliefs about the world, we can easily reject certain conclusions that seem to be looming the face of skeptical challenges.

Consider then the problem of evaluating our epistemic norms. Assume that according to reliabilism, an epistemic norm is proper just if reliable under the conditions of its normal use. So certifying that some epistemic norm is proper requires canvassing empirical evidence of its reliability under those circumstances. Explaining the features in virtue of which the norm is proper would be accomplished by pointing to the features that makes it reliable. Say that some subject $S$ is justified in relying on an epistemic norm just in case doing so results from a reliable process for the selection of proper epistemic norms to rely upon. So, explaining that $S$ is justified in relying on a particular epistemic norm would require identifying such processes that led to trusting this norm. Finally, a belief to the effect that some epistemic norm is proper is itself justified just if acquired and sustained by a reliable process. So for the reliabilist to explain how we can be justified in believing certain epistemic norms to be proper requires pointing to such processes. The explanation, of course, fails to respect the privileged class constraint.

Unsurprisingly, many epistemologists have objected that the violation of the privileged class constraint is question-begging. Here is Fumerton: 'None of this, of course, will make the skeptic happy. You cannot use perception to justify the reliability of perception! You cannot use memory to justify the reliability of memory! You cannot use induction to justify the reliability of induction! Such attempts to respond to the skeptic's concerns involve blatant, indeed pathetic, circularity.' (Fumerton 1994: 337-8; Fumerton 1995: chapter 6).

The strong normative naturalist can offer a response to this worry, however. For simplicity, consider just the problem of evaluating epistemic norms. The strong normative naturalist can distinguish several parts of this enterprise. One is the task of providing a dialectically satisfactory response to a challenge posed by someone who is assumed - if only for the sake of argument to seriously doubt the propriety of a particular epistemic norm EN. Clearly, in this kind of enterprise one cannot assume EN to be a proper epistemic norm. Indeed, this stems from a general feature of argumentative debate. When proposing an argument to someone who seriously questions whether there are reasons to accept some proposition $p$, one cannot appeal to $p$ itself, or to premises the truth or justification of which depend $p$. So, we can understand what motivates the privileged class constraint, and see why it applies to the problem of providing a dialectically appropriate response to a skeptic.

However, the strong normative naturalist can insist that the crucial task is not that of convincing a presumed skeptic, but the different one of explaining the epistemic status of our epistemic norms. Providing a successful explanation of 
this kind is very different from providing a dialectically acceptable argument to someone who is assumed to seriously question the propriety of some epistemic norm. Suppose that, as reliabilists we seek to explain the epistemic properties of a certain epistemic norm EN. And suppose that, when providing such reliabilist explanation of the features of EN, we rely on the use of EN. Would this epistemic circularity (Alston 1986), at it is often called, invalidate the explanation we seek to mount? It seems not. Explanations generally appeal to facts that we know or justifiably believe. When, as is generally the case, we know or justifiably believe facts by relying on epistemic norms, they must be proper norms. So, successful explanations require reliance on proper epistemic norms. Clearly, this requirement applies to the epistemic circularity at hand. So, if the explanation of how we can be justified in relying on EN or in believing that EN is a proper epistemic norm itself trades on beliefs whose justification depends on the use of EN, then the explanation presupposes that EN is indeed a proper norm. So, if EN is in fact a proper norm, that is, if $\mathrm{EN}$ is reliable under the appropriate circumstances, then the explanation is successful, at least as far as EN is concerned, despite the epistemic circularity. So, the epistemic circularity at hand need not invalidate the explanation we seek.

What the presence of this kind of epistemic circularity does show, however, is that someone doubting the propriety of EN should not let herself rationally convince by the explanation we offer, since she rejects part of the basis for the explanation. But, as we have seen, the strong normative naturalist can insist that the success of the explanation on offer is unaffected by this. The aim is to

\section{How is knowledge possible?}

Barry Stroud has, in many writings, pressed what is effectively a related objection to strong normative naturalism. He poses a transcendental question: How is knowledge possible? As we have seen, the reliabilist has a simple answer. Knowledge just is true belief formed by a reliable process under appropriate circumstances (ignoring Gettier complications). So, knowledge is possible because we are beings equipped with a range of ways of forming beliefs that are reliable and regularly lead to true beliefs under the appropriate circumstances. This explanation of how knowledge is possible relies heavily on matters known, of course. But it is not thereby invalidated. One cannot explain a fact by itself. But clearly one can explain the fact that we are capable of knowing facts by appealing to other facts, knowledge of which are presupposed in the explanation. Explaining how knowledge is possible is not convincing a skeptic.

Stroud finds this deeply unsatisfactory. As he says: "The difficulty in understanding how sense-perception gives us knowledge [...] is that it seems at least possible to perceive what we do without thereby knowing something about the things around us'. According to Stroud, the transcendental question invites us to explain how we nevertheless can have knowledge of the world. As he says, 'Given the apparent 'obstacle', how is our knowledge possible?' (Stroud 2002: 56). In other places Stroud says that a philosophical theory of knowledge must provide 'an account of our knowledge of the world that would make all of it intelligible to us all at once' (Stroud 2002: 8)

Stroud seems to assume that a satisfactory answer to the transcendental question must also answer a skeptical challenge, or a range of them. Thus, when 
explaining how knowledge is possible we are permitted to appeal only to features that could feature in a dialectically acceptable answer to a skeptic. This, in turn, means observing the privileged class constraint. On this construal of the question 'How is knowledge possible?' strong normative naturalism fails to provide a satisfactory answer.

Clearly, however, the strong normative naturalist can respond that Stroud conflates the dialectical requirements relevant when responding to a skeptic with requirements reasonably imposed on an explanation of what knowlegde is and how it is possible. Thus, strong normative naturalism promises a nonskeptical explanation of how we can have knowledge and justified belief, but one that cannot convince a presumed skeptic. What is decisive is that failing to respect the privileged class constraint carries no dramatic epistemological consequences.

Note that the fate of strong and weak normative naturalism is independent of descriptive naturalism. One might reject descriptive naturalism, and still advocate lifting the privileged class constraint. Note also that, contrary to what is often assumed, normative naturalism does not depend on the rejection of the a priori. One can concede that some propositions can be known a priori and yet advocate normative naturalism. One can even accept that the propriety of some epistemic norms can be known a priori, and yet adopt the general strategy of normative naturalism. And there might be a very good reason to do so. Even if the propriety of some epistemic norms could be established a priori, this is unlikely to provide us with the epistemic advice that we need. We need to establish, it seems, which specific epistemic norms are best (or at least good enough) given the actual 'powers and limits of the human cognitive system' (Goldman, 1978): 510, and given our wider non-epistemic interests and concerns. Even on the most optimistic views about what might be known a priori, it is hard to see how this could be accomplished without resorting to empirical investigations.

\section{Naturalism about methodology in epistemology}

A second dimension of naturalistic epistemology concerns the method by which epistemological questions should be pursued. The methodological naturalist rejects the exclusive commitment to philosophical methods in epistemology, and holds that we should include methods and empirical findings from various parts of science, including biology, cognitive psychology and many other disciplines.

Note that one can advocate the use of non-empirical methods as a necessary supplement to philosophical methods, or one can reject philosophical methods as entirely unsuitable for epistemology. Note also that methodological naturalism may be applied selectively to the various projects of epistemology. For example, one can reject methodological naturalism regarding the descriptive project, but accept it regarding the normative project.

Hilary Kornblith is a prominent advocate of methodological naturalism with respect to the descriptive project. According to Kornblith, a theory of knowledge should provide a correct account of the nature of knowledge, as distinct from an account of the concept of knowledge. And just as an analysis of the concept of aluminium will hardly reveal the nature of aluminium, analysis of the concept of knowledge is unhelpful for understanding what knowledge is. Rather, we should 'examine apparently clear cases of knowledge to see what it is 
that they have in common.' We must, says Kornblith, 'examine the various psychological mechanisms by which knowledge is produced and retained in order to see what, if anything, they have in common.' (Kornblith, 1999: 161; cf. Kornblith 2002: chapter 1 and 2).

Kornblith's view remains quite controversial, even among philosophers otherwise sympathetic to naturalism. One cause of concern is the very idea that the concept of knowledge is a natural kind concept. This seems highly contentious - there may be no underlying theoretical unity to cases of knowledge, apart from the fact that they, at least according to reliabilism, all involve true belief formed by reliable processes (Goldman 2005: 405).

Kornblith is indeed sympathetic to reliabilism. But reliabilism seems best defended by philosophical methods, or at any rate this is how the view has been defended in recent epistemology. Reliabilism is justified by the fact that this theory (allegedly) captures a broad range of our considered epistemic judgment concerning putative cases of knowledge and justified belief. Empirical investigations could of course have some role in providing counter-examples to proposed analyses of knowledge and justification, thereby forcing revisions. The problem, however, is that the counterexamples needed would seem to be readily available anyway (Feldman 1999). So, is not clear that methodological naturalism could be a vital part of the descriptive project.

However, others have questioned precisely the role of considered epistemic judgments are assumed to have in philosophical methods, and this points to a different form of methodological naturalism. In a widely debated paper, Weinberg, Nichols, and Stich call attention to the fact that considered epistemic judgments might vary across cultures and social strata. And indeed, preliminary empirical findings did suggest some interesting differences in considered epistemic judgment. For example, students of Indian, Pakistani and Bangladeshi decent were found to be significantly less willing to characterize a typical Gettier case as one in which one does not have knowledge than were their western counterparts (Weinberg et al., 2001).

One might, of course, question the specific findings and methods in Weinberg, Nichols and Stich. However, assuming that considered epistemic judgments are indeed relevant for understanding our epistemic concepts and the nature of epistemic properties, it seems that empirical surveys of the actual set of judgments that people have would be indispensable for more robust relevant information. At least such empirical surveys would seem necessary to establish the considered epistemic judgment of professional epistemologists are not merely idiosyncratic and therefore beyond general interests, as indeed Bishop and Trout suspect. (Bishop and Trout 2005a).

Even if this problem is overcome Bishop and Trout's discussion points to a wider methodological issue concerning the relevance of the descriptive project for the normative concerns in epistemology. It is often, if only tacitly, assumed that since epistemic notions such as knowledge and justification are essentially normative, understanding their nature will immediately lead to prescriptions regarding how to reason and conduct inquiry. It is not obvious, however, that standard theories of knowledge and justification such as fundamentalism, coherentism, reliabilism, contextualism really are prescriptive in this way. These theories are, at their core, descriptive theories aiming to capture our considered epistemic judgment, or providing accounts of the content of our epistemic 
concepts. But why pay so much attention to our actual considered set of epistemic judgments, or our actual epistemic concepts? Why not turn directly to the to the problem of devising better ways of reasoning and conducting inquiry?

\section{References}

ALSTON, W. P. (1986) Epistemic Circularity. Philosophy and Phenomenological Research, 47, 1-30.

BISHOP, M. \& TROUT, J. D. (2005a) The Pathologies of Standard Analytic Epistemology. Nous, 39, 696-714.

BISHOP, M. A. \& TROUT, J. D. (2005b) Epistemology and the psychology of human judgment, Oxford, Oxford University Press.

BLACKBURN, S. (1998) Ruling passions : a theory of practical reasoning, Oxford, Clarendon Press.

BONJOUR, L. (1994) Against Naturalized Epistemology. Midwest Studies in Philosophy, 19, 283-300.

BONJOUR, L. (1998) In Defense of Pure Reason, Cambridge, Cambridge University Press.

CHRISMAN, M. (2007) From Epistemic Contextualism to Epistemic Expressivism. Philosophical Studies, 135, 225-254.

CUNEO, T. (2007) The normative web : an argument for moral realism, Oxford, Oxford University Press.

FELDMAN, R. (1999) Methodological Naturalism in Epistemology. IN GRECO, J. \& SOSA, E. (Eds.) The Blackwell Guide to Epistemology.

FIELD, H. (1998) Epistemological nonfactualism and the a prioricity of logic. Philosophical Studies, 92, 1-24.

FOLEY, R. (1994) Quine and Naturalized Epistemology. IN FRENCH, P. A., UEHLING, J., THEODORE E. \& WETTSTEIN, H. K. (Eds.) Midwest Studies in Philosophy. Philosophical Naturalism. Notre Dame, University of Notre Dame Press.

FUMERTON, R. A. (1994) Skepticism and Naturalistic Epistemology. IN FRENCH, P. A., UEHLING, J., THEODORE E. \& WETTSTEIN, H. K. (Eds.) Midwest Studies in Philosophy. Philosophical Naturalism. Notre Dame, IN, University of Notre Dame Press.

FUMERTON, R. A. (1995) Metaepistemology and skepticism, Lanham, Md., Rowman \& Littlefield.

GIBBARD, A. (1990) Wise choices, apt feelings : a theory of normative judgement, Oxford, Clarendon.

GIBBARD, A. (2003) Thinking how to live, Cambridge, Mass. ; London, Harvard University Press.

GOLDMAN, A. (1992a) Epsitemic Folkways and Scientific Epistemology. IN GOLDMAN, A. (Ed.) Liaisons: Philosophy Meets the Cognitive and Social Sciences. Cambridge, Mass., MIT Press.

GOLDMAN, A. (1994) Naturalistic Epistemology and Reliabilism. IN FRENCH, P. A., UEHLING, J., THEODORE E. \& WETTSTEIN, H. K. (Eds.) Midwest Studies 
in Philosophy. Philosophical Naturalism. Notre Dame, IN, University of Notre Dame Press.

GOLDMAN, A. (2005) Kornblith's Naturalistic Epistemology. Philosophy and Phenomenological Research, 71, 403-410.

GOLDMAN, A. I. (1978) Epistemics: the Regulative Theory of Cognition. Journal of Philosophy, 75, 509-523.

GOLDMAN, A. I. (1979) What Is Justified Belief. Justification and Knowledge.

GOLDMAN, A. I. (1986a) Epistemology and Cognition. Cambridge: Harvard Univ Pr.

GOLDMAN, A. I. (1986b) Epistemology and cognition, Cambridge, Mass., Harvard University Press.

GOLDMAN, A. I. (1992b) Liaisons : philosophy meets the cognitive and social sciences, Cambridge, Mass., MIT Press.

KIM, J. (1988) What Is "Naturalized Epistemology"? IN TOMBERLINE, J. E. (Ed.) Philosophical Perspectives, Epistemology. Atascadero, CA, Ridgeview Publishing Co.

KITCHER, P. (1992) The Naturalists Return. Philosophical Review, 101, 53-114.

KORNBLITH, H. (1999) In Defense of a Naturalized Epistemology. IN GRECO, J. \& SOSA, E. (Eds.) The Blackwell Guide to Epistemology. Blackwell.

KORNBLITH, H. (2002) Knowledge and its place in nature, Oxford, Clarendon.

KVANVIG, J. L. (2003) The value of knowledge and the pursuit of understanding, Cambridge, UK ; New York, Cambridge University Press.

LAUDAN, L. (1990) Normative Naturalism. Philosophy of Science, 57, 44-59.

LEHRER, K. (1999) Reply to Van Cleve. Philosophy and Phenomenological Research, LIX, 1068-71.

MACKIE, J. L. (1977) Ethics : inventing right and wrong, Harmondsworth, Penguin.

MAFFIE, J. (1990) Recent Work on Naturalized Epistemology. American Philosophical Quarterly, 281-293.

QUINE, W. V. (1969) Epistemology Naturalized. Ontological Relativity and Other Essays. New York, Columbia University Press.

QUINE, W. V. (1975) The Nature of Natural Knowledge. IN GUTTENPLAN, S. (Ed.) Mind and Language. Oxford University Press.

QUINE, W. V. (1986) Reply to Morton White. IN HAHN, L. \& SCHILPP, P. (Eds.) The Philosophy of W.V. Quine. La Salle, IL, Open Court.

STICH, S. P. (1990) The fragmentation of reason : preface to a pragmatic theory of cognitive evaluation, Cambridge, Mass., MIT Press.

STRAWSON, P. F. (1952) Introduction to Logical Theory, pp. x. 266. Methuen \& Co.: London; John Wiley \& Sons: New York.

STRAWSON, P. F. (1985) Skepticism and naturalism : some varieties : the Woodbridge lectures 1983, London, Methuen.

STROUD, B. (2002) Understanding Human Knowledge: Philosophical Essays. Review of Metaphysics, vol, 56.

VAN CLEVE, J. (1985) Epistemic Supervenience and the Circle of Belief. Monist: An International Quarterly Journal of General Philosophical Inquiry, 68.

VAN CLEVE, J. (1999) Epistemic Supervenience Revisited. Philosophy and Phenomenological Research, LIX, 1049-1055.

WEINBERG, J., NICHOLS, S. \& STICH, S. (2001) Normativity and Epistemic Intuitions. Philosophical Topics, 29, 429-60. 
Klemens Kappel (born 1964) is associate professor in philosophy at the University Copenhagen. His research interests are in epistemology, in particular social epistemology, but he has also published in ethics, metaethics. 